\title{
Implementation and effectiveness of continuous kangaroo mother care: a participatory action research protocol
}

\author{
Marzieh Mohammadi ${ }^{1}$, Anne-Marie Bergh², Mohammad Heidarzadeh ${ }^{3}$, Mahammadbagher Hosseini ${ }^{3}$ \\ Niloufar Sattarzadeh Jahdi ${ }^{4}$, Leila Valizadeh ${ }^{5}$, Behzad Sarvaran ${ }^{6}$ and Sevil Hakimi ${ }^{1,7^{*}}$ (D)
}

\begin{abstract}
Background: The efficacy of continuous kangaroo mother care (C-KMC) in reducing neonatal mortality and morbidity among low birthweight and premature infants has been confirmed. Despite the recommendations of the World Health Organization, UNICEF, and the Ministry of Health of Iran to use C-KMC for eligible hospitalized neonates, this type of care is not performed due to implementation problems. This protocol aims to describe the design, implementation, and assessment of C-KMC in one tertiary hospital by means of participatory action research.

Methods: The objective of this study is to design and implement a C-KMC program for neonates that will be performed in two phases using a stages-of-change model. The first phase will be conducted in three consecutive activities of designing, implementing, and assessing the introduction of C-KMC. The second phase of the study has a before-and-after design to assess the effectiveness of C-KMC by comparing the length of preterm neonates' stay in hospital and exclusive breastfeeding at discharge before and after implementing C-KMC.

Discussion: KMC is an important component of neonatal developmental care as part of family-centered care. Applying this type of care requires creating appropriate strategies, budget allocation, and clear and coordinated planning at different levels of the health system. The stages-of-change model is one of the appropriate approaches to the implementation of C-KMC.
\end{abstract}

Keywords: Continuous kangaroo mother care, Health services research, Premature infant, Health plan implementation

\section{Background}

An estimated 2.5 million newborns die every year, of which the vast majority of deaths occurs in low- and lower-middle-income countries [1]. Premature birth is the leading cause of neonatal deaths around the world,

\footnotetext{
* Correspondence: hakimis@tbzmed.ac.ir

'Student Research Center Committee, Tabriz University of Medical Science, Tabriz, Iran

${ }^{7}$ Department of midwifery, School of Nursing and midwifery, Research center of psychiatry and behavioural science, Tabriz University of Medical Science, Tabriz, Iran

Full list of author information is available at the end of the article
}

accounting for $47 \%$ of deaths in children below 5 years of age in 2018 [2]. In addition to premature infants being at greater risk for neonatal mortality, these infants suffer more long-term health problems, physical disabilities, and lifelong mental disabilities than term infants [3]. Providing care for premature newborns imposes a heavy burden on healthcare $[4,5]$ and effective interventions require high technology, skilled staff, and an efficient care system in addition to high costs [6].

In line with the goals of sustainable development to reduce infant mortality in low-income and middle-

(c) The Author(s). 2021 Open Access This article is licensed under a Creative Commons Attribution 4.0 International License, which permits use, sharing, adaptation, distribution and reproduction in any medium or format, as long as you give appropriate credit to the original author(s) and the source, provide a link to the Creative Commons licence, and indicate if changes were made. The images or other third party material in this article are included in the article's Creative Commons licence, unless indicated otherwise in a credit line to the material. If material is not included in the article's Creative Commons licence and your intended use is not permitted by statutory regulation or exceeds the permitted use, you will need to obtain permission directly from the copyright holder. To view a copy of this licence, visit http://creativecommons.org/licenses/by/4.0/. The Creative Commons Public Domain Dedication waiver (http://creativecommons.org/publicdomain/zero/1.0/) applies to the data made available in this article, unless otherwise stated in a credit line to the data. 
income countries, we need low-cost care with high effectiveness [7].

KMC is a cost effective complementary method of caring for stable low birthweight (LBW) and preterm neonates $[8,9]$ that can contribute to improving the quality of care, as it ensures constant temperature regulation and improved survival of these infants. C$\mathrm{KMC}$ is one of the 10 recommendations of the World Health Organization (WHO) for providing care for premature neonates [7]. Evidence-based studies have shown the efficacy of KMC to reduce mortality and morbidity in preterm neonates, prevent hypothermia and infection, improve maternal-infant attachment and increase the duration of exclusive breastfeeding [8-14].

KMC can be provided intermittently and continuously. Nyqvist et al. describe the difference as follows: "The hallmark of KMC is the kangaroo position: the infant is cared for skin-to-skin vertically between the mother's breasts and below her clothes, $24 \mathrm{~h} /$ day, with father / substitute(s) participating as KMC providers. Intermittent KMC (for short periods once or a few times per day, for a variable number of days) is commonly employed in high-tech neonatal intensive care units." [15].

Studies have shown that the duration of KMC can be increased by improving facilities [16]. The longer the care duration is, the greater the benefits obtained from it are and the better consequences of physical, mental and emotional development are for the premature infant who needs this care $[6,15]$.

Despite the recommendations of the $\mathrm{WHO}$ and UNICEF, on the use of C-KMC for eligible hospitalized neonates, this type of care is not implemented because of various barriers such as lack of physicians" and nurses 'preferences as well as limitation in appropriate place for carry out C-KMC. All cross-sectional studies conducted in Iran so far have focused on intermittent $\mathrm{KMC}[6,17,18]$ and the number of hours of KMC per day was below the recommended average for intermittent KMC [19].

\section{Study aim}

This protocol describes a proposed study aimed at designing a C-KMC program for neonates and implementing and evaluating this program and the effect of $\mathrm{C}$ KMC in a teaching hospital in North West Iran. The hospital had nearly 6500 deliveries in 2018 , with $8 \%$ of neonates being preterm. There is a level III neonatal intensive care unit (NICU) with 25 beds and a neonatal ward with 15 beds.

At present, infants admitted to the neonatal ward or NICU receive 1 to 2 hours of KMC per shift at this hospital. According to the protocol, the minimum duration of this care is 1 hour. Care will continue after 1 hour as long as the mother has the ability and patience to do it.
Typically, mothers can do this care for more than 2 hours in a shift. Consequently, each baby receives care for three to 6 hours (according to the mother's ability) until now and before performing this plan.

The specific objectives of this study are to:

1. Identify the barriers and problems related to the introduction of $\mathrm{C}-\mathrm{KMC}$

2. Implement $\mathrm{C}-\mathrm{KMC}$ according to the principles of action research

3. Evaluate progress with C-KMC implementation

4. Compare exclusive breastfeeding rates at the time of hospital discharge for a period before and after introducing C-KMC

5. Compare the duration of hospitalization of neonates before and after the introduction of C-KMC

\section{Study design}

This study uses a mix- method design, which will be conducted in two phases. The first phase will use a participatory action research approach in three consecutive activities (design, implementation and evaluation) as part of the introduction of C-KMC. The second phase of the study is a quantitative before-and-after study aimed at assessing the effectiveness of C-KMC. Table 1 gives an overview of the study design.

\section{First study phase: tracking implementation}

The participatory action research in this study is based on the approach of the stages-of-change model developed by Bergh et al. [20]. This model is a useful model for introducing C-KMCs in hospitals and is almost consistent with McNiff's research action [21]. The stages-of-change model includes three main change phases, namely pre-implementation (readiness of stakeholders), implementation (readiness of system) and institutionalization (quality of care). Each phase consists of two steps or stages. Figure 1 illustrates this model for implementing C-KMC. The research group will use the results of the first study phase to inform the authorities about current care and necessary adaptations to improve the care with a view to get their commitment for the further administration and expansion of C-KMC.

\section{Second study phase: measuring effectiveness of C-KMC} In this study phase, the effectiveness of C-KMC implementation will be assessed by means of two measures in a before-after comparison: length of eligible neonates' stay in hospital and exclusive breastfeeding rate at the time of hospital discharge. 
Table 1 Overview of the study design

\begin{tabular}{|c|c|c|}
\hline & Phase 1: Tracking C-KMC implementation & $\begin{array}{l}\text { Phase 2: Measuring effectiveness of C- } \\
\text { KMC }\end{array}$ \\
\hline Intervention & Continuous kangaroo mother care & \\
\hline Study design & Participatory action research & $\begin{array}{l}\text { Before-after comparison of non-C-KMC and C- } \\
\text { KMC neonates }\end{array}$ \\
\hline Aim & $\begin{array}{l}\text { To implement continuous KMC in the study setting and identify barriers / } \\
\text { challenges to the implementation of C-KMC }\end{array}$ & To investigate the effectiveness of C-KMC \\
\hline Hypothesis & Not applicable & $\begin{array}{l}\text { Continuous KMC: } \\
\text { 1. reduces the length of hospital stay of } \\
\text { preterm neonates / neonates }<2500 \mathrm{~g} \\
\text { 2. increases the rate of exclusive } \\
\text { breastfeeding at discharge }\end{array}$ \\
\hline Study setting & General hospital in North West Iran, level III NICUa & \\
\hline Participants & $\begin{array}{l}\text { - Mothers with preterm neonates } \\
\text { - Nurses and midwives } \\
\text { - Managers and health policy makers }\end{array}$ & - Preterm neonates \\
\hline Sampling & $\begin{array}{l}\text { - Purposive sampling } \\
\text { - Sample size: until data saturation is reached }\end{array}$ & $\begin{array}{l}\text { - Consecutive sample (before and after C-KMC } \\
\text { implementation) } \\
\text { - Sample size: } 208=104 \text { per group }\end{array}$ \\
\hline $\begin{array}{l}\text { Data collection } \\
\text { tools }\end{array}$ & $\begin{array}{l}\text { 1. Interview guide (for focus group discussions and individual interviews) } \\
\text { 2. Standardized progress-monitoring tool: } \\
\text { - Observations of service provision, care and records } \\
\text { - Interviews with health care providers (nurses, doctors, etc.) }\end{array}$ & $\begin{array}{l}\text { Data collection sheet (questionnaire): } \\
\text { - Length of hospitalization (total and length } \\
\text { of days in C-KMC) } \\
\text { - Feeding method(s) at discharge } \\
\text { - Other characteristics (e.g. gestational age } \\
\text { and sex) - see Table } 2 \text { for details }\end{array}$ \\
\hline $\begin{array}{l}\text { Data collection } \\
\text { process }\end{array}$ & $\begin{array}{l}\text { - Focus group discussions (health care providers and managers) and individual } \\
\text { interviews (mothers) } \\
\text { - Application of the progress-monitoring tool }\end{array}$ & $\begin{array}{l}\text { Completion of the data collection sheet using } \\
\text { data from the neonates' medical file }\end{array}$ \\
\hline Data analysis & $\begin{array}{l}\text { - Qualitative content analysis } \\
\text { - Software: MAXQDA10 }\end{array}$ & $\begin{array}{l}\text { - Data with normal distribution: paired t-test; } \\
\text { Pearson correlation coefficient; ANOVA } \\
\text { - Paired nominal data: McNemar's test } \\
\text { - Software: SPSS version } 24\end{array}$ \\
\hline $\begin{array}{l}\text { Ethical } \\
\text { considerations }\end{array}$ & Written consent from participants before interviews and focus groups & $\begin{array}{l}\text { Consent from parents or hospital } \\
\text { management to use data }\end{array}$ \\
\hline
\end{tabular}

${ }^{a}$ NICU level III Neonatal intensive care unit that is capable of caring for neonates $<32$ weeks or $<1500 \mathrm{~g}$ with professional personnel including neonatal nurses who are available 24 hours a day, ANOVA analysis of variance, SPSS Statistical Package for Social Sciences, C-KMC contionuse kangaroo mother care

Methods

\section{Description of continuous kangaroo mother care as intervention}

The following steps will be taken to initiate the introduction of C-KMC:

- Identifying the roles of individuals and training them in the necessary issues.

- Compiling instructions and forms in the process of getting ready for $\mathrm{C}-\mathrm{KMC}$ administration.

- Preparing the physical space for C-KMC and ablution facilities, as well as acquiring furniture (e.g. beds and lockers or wardrobes) and organizing catering services to provide meals for mothers.

Once the $\mathrm{KMC}$ ward is prepared, the implementation of $\mathrm{C}-\mathrm{KMC}$ will include the following:
- The pediatrician will identify infants eligible for CKMC.

- Mothers will be counselled on how to do C-KMC including skin-to-skin care, breastfeeding and the requirements for follow-up care after discharge from the hospital.

- Mothers will be allowed to freely move, watch TV, study and do other activities of interest.

As part of the implementation, the research group will identify the strengths and weaknesses of the program and make the necessary adjustments and revisions to establish C-KMC as routine practice in the KMC ward.

\section{Sampling}

Phase 1 of the study will investigate the challenges and barriers to the introduction of $\mathrm{C}-\mathrm{KMC}$ in line with the 


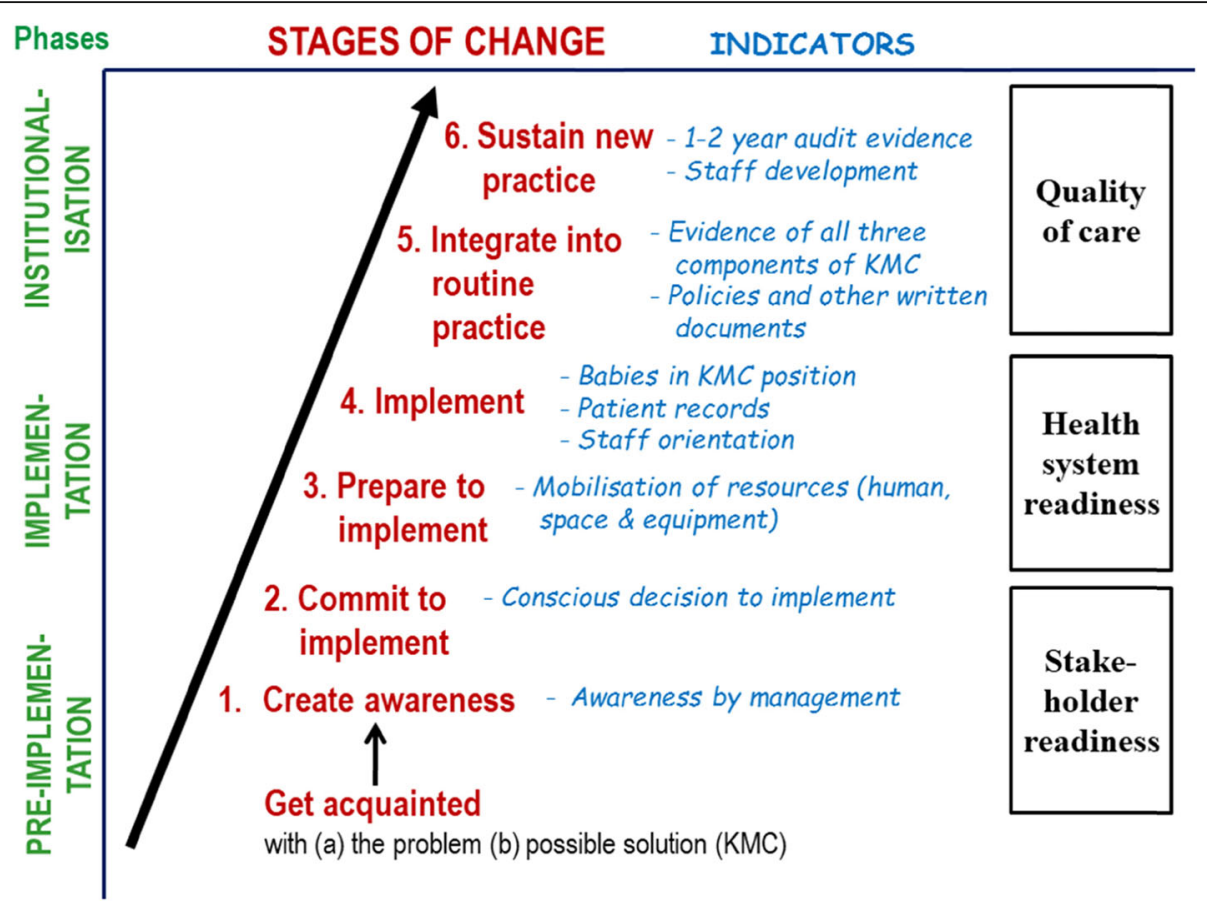

Fig 1 Stages-of-change model for implementing C-KMC

first stage of the stages-of-change model. Participants at this stage will include mothers with preterm neonates, nurses, midwives, managers, and health policy makers who are associated with the neonatal ward where CKMC is to be implemented. They will be selected through purposeful sampling to participate in focus group discussions and individual interviews. Sampling will continue until the data is saturated, i.e. no new information is obtained [22].

Participants for the focus groups will be healthcare providers and managers allocated to homogeneous groups (e.g. nurses or doctors only) and heterogeneous groups (e.g. health officials, hospital directors, nursing services managers, nurses and doctors in the same group). This will enable the evaluation of challenges, obstacles and opportunities for improvement from various perspectives. Mothers will be interviewed individually with a view to identifying their special needs.

Phase 2 of the study will include two groups of premature neonates as study participants: those that received C-KMC (intervention) and those that did not receive $\mathrm{C}-\mathrm{KMC}$ (control). The sample size in this part of the study was determined according to the criteria used in the study conducted by Mishra et al. [23]. For the days of stay in hospital $(\mathrm{m} 1=14, \mathrm{SD} 1=7, \mathrm{~m} 2=12$, and SD2 =6), $\alpha=0.05 \beta=0.2$, the sample size was determined to be 102 people in each group. The total sample size was estimated to be 204 participants. The ratio of the intervention to control group will be 1 to 1 .
Inclusion criteria for preterm neonates in both groups are birthweight ranged between 1200 and 2500 g, stable condition, spontaneous breathing (no need for CPAP / ventilator), no oxygen therapy, ability to feed by tube or directly from the breast, and absence of maternal disease (e.g. active tuberculosis and severe maternal depression and anxiety). All infants included in this phase of the study would have received intermittent $\mathrm{KMC}$ in the NICU. For the intervention group, an additional inclusion criterion is pediatrician permission to initiate $\mathrm{C}$ KMC.

Exclusion criteria include neonates with problems such as hypothermia (despite efforts to keep the baby warm), seizure, breathing problems (apnea, chest retraction, grunting, nasal flaring, and cyanosis), drowsiness (excessive sleep or reduced activity), and jaundice requiring phototherapy along with an unstable condition. In addition, maternal unwillingness to practice C-KMC will also be an exclusion criterion.

\section{Data collection and measurements}

Phase 1 (introduction of C-KMC) will include qualitative focus group and individual interviews that will be conducted with an interview guide with a few predetermined questions, followed by open-ended, in-depth exploratory questions relating to the barriers to C-KMC. Every interview will have a moderator and an administrator. 
Information gathered in group discussions can be clarified and explored further by conducting individual interviews. In the focus groups information will be obtained by involving all members in the discussion and exploring proposed solutions for any barriers reported. The strengths and weaknesses of each solution will be discussed and any further barriers to implementation of the process.

Suggested questions will be:

1. How familiar were you with C-KMC?

2. How interested are you in $\mathrm{C}-\mathrm{KMC}$ ?

3. To what extent is performing $\mathrm{C}-\mathrm{KMC}$ necessary in neonatal unit?

4. What are the most important barriers in launching $\mathrm{C}-\mathrm{KMC}$ in your opinion?

5. How can these barriers be removed?

All interviews will be audio-recorded with the participants' permission and will last between $45 \mathrm{~min}$ and 1 hour. Interviews will take place in a private room in the hospital.

The standardized tool developed from Bergh et al.'s [20] stages-of-change model will be used to monitor the implementation progress of C-KMC. This tool has 18 sections, of which some are completed by health personnel and some are completed as part of the observation of the unit and the C-KMC implementation process. The tool uses a scoring system with a maximum of 30 points. The score obtained by a hospital indicates the status of the hospital in terms of implementing CKMC. Obtaining a score more than 10 indicates that the hospital is on track with implementing C-KMC. A score of more than 17 indicates that the hospital is on the track with providing routine $\mathrm{C}-\mathrm{KMC}$, whereas a score of more than 24 indicates that the care has been institutionalized and is moving towards the stage of sustaining practice [20].

Phase 2 (evaluating the effectiveness of $\mathrm{C}-\mathrm{KMC}$ ) will employ a researcher-developed questionnaire (data collection sheet) as data collection tool. Possible items to be included in the questionnaire are listed in Table 2. The questionnaire will be sent to 10 pediatricians, nursing faculty members, midwives and nurses working in the neonatal intensive care unit to assess content validity. Their comments will be accommodated in the final version of the tool.

\section{Data analysis}

\section{Phase 1}

Focus group and individual interviews will be transcribed verbatim and transcriptions will be read and reread several times to identify meaningful units to be coded and from which themes will be extracted and categorized. MAXQDA10 software will be used for doing qualitative content analysis according to a conventional approach [24]. Four criteria: credibility, reliability, conformability, and transferability, will be applied to increase the trustworthiness of qualitative findings [25].

Data derived from the progress-monitoring tool will be analyzed quantitatively and qualitatively.

\section{Phase 2}

'The quantitative cross-sectional data will be compared before and after the implementation of C-KMC to specify to what extent the change has been effective.'

Quantitative data obtained from the completed data collection sheet will be analyzed with SPSS version 24 software to generate descriptive and inferential statistics. Participants in the $\mathrm{C}-\mathrm{KMC}$ and non-C-KMC groups will be matched for gestational age and sex. For data with a normal distribution, the paired t-test, Pearson correlation coefficient, and ANOVA will be used; for paired nominal data, McNemar's test will be used.

\section{Discussion}

According to the WHO recommendations, every neonate should receive the highest quality of care [26]. Studies have shown that the NICU faces the greatest number of care challenges, of which the provision of poor quality neonatal care is the most important challenge [27]. Nursing errors are an example of the dangers working in a NICU, where shortage of staff and high workload are common [28]. Family-centered care engages parents in providing care for premature neonates, reduces nurses' workload and enhances parental confidence and competence in newborn care. WHO has considered KMC to be a part of family-centered care for sick and small infants [6].

KMC is an important component of neonatal developmental care that requires guiding and promoting clinical behavioral changes in medical staff [29].

In addition, KMC has many proven benefits. Studies have shown that KMC reduces neonatal crying, improves physiological conditions, and stabilizes cardiac and vascular status of neonates [30]. Skin-to-skin care reduces the cortisol levels in neonates and mitigates pain in these infants, making the painful neonatal processes more tolerable [31].

The longer the care duration is, the greater the benefits obtained [15, 32].

C-KMC improves neonatal development and reduces risk of growth retardation in the first 24 months. Its benefits can be observed even in adolescence and adulthood [18]. Applying this care requires the development of appropriate strategies, budget allocation and clear and coordinated planning at different levels of the health 
Table 2 Data to be captured in Phase 2 of the study

\begin{tabular}{|c|c|c|}
\hline Focus areas & Specific information & \\
\hline \multirow[t]{3}{*}{ Pregnancy history } & \multicolumn{2}{|l|}{ Pregnancy risk factors / complications } \\
\hline & \multicolumn{2}{|l|}{ Delivery mode } \\
\hline & \multicolumn{2}{|l|}{ Maternal age } \\
\hline \multirow[t]{6}{*}{ Neonatal characteristics } & \multicolumn{2}{|l|}{ Gestational age } \\
\hline & \multicolumn{2}{|l|}{ Sex } \\
\hline & Medical needs at birth and in NICU & $\begin{array}{l}\text { - Need for resuscitation } \\
\text { - Need for respiratory support } \\
\text { - Medical complications } \\
\text { - Infection } \\
\text { - Intervention therapies } \\
\text { - Medication prescriptions }\end{array}$ \\
\hline & Weight & $\begin{array}{l}\text { - Birth weight (on admission to NICU/neonatal ward) } \\
\text { - Weight on admission to C-KMC } \\
\text { - Discharge weight }\end{array}$ \\
\hline & Head circumference & $\begin{array}{l}\text { - At birth } \\
\text { - On admission to C-KMC } \\
\text { - On discharge }\end{array}$ \\
\hline & Body temperature & $\begin{array}{l}\text { - On admission } \\
\text { - During hospitalization in the NICU } \\
\text { - During C-KMC } \\
\text { - On discharge }\end{array}$ \\
\hline \multirow[t]{3}{*}{ Operational characteristics } & $\begin{array}{l}\text { Type of feeds - breast milk (tube/finger/direct), formula, } \\
\text { mixed) }\end{array}$ & $\begin{array}{l}\text { - In NICU } \\
\text { - In C-KMC } \\
\text { - At discharge }\end{array}$ \\
\hline & Practice of C-KMC & $\begin{array}{l}\text { - Intermittent KMC in NICU (Yes/No) } \\
\text { - Mean duration of C-KMC (hours per day) } \\
\text { - Maternal cooperation during C-KMC } \\
\text { - Attendant to assist / substitute mother in doing C- } \\
\text { KMC } \\
\text { - Family support with and attitudes towards KMC }\end{array}$ \\
\hline & Duration of hospitalization (days) & $\begin{array}{l}\cdot \ln N I C U \\
\cdot \ln C-K M C\end{array}$ \\
\hline Discharge & \multicolumn{2}{|l|}{ Discharge permission signed by doctor } \\
\hline \multirow{4}{*}{$\begin{array}{l}\text { Parental socio- } \\
\text { demographic }\end{array}$} & \multicolumn{2}{|l|}{ Mother's educational level } \\
\hline & \multicolumn{2}{|l|}{ Father's educational level } \\
\hline & \multicolumn{2}{|l|}{ Place of residence } \\
\hline & \multicolumn{2}{|l|}{ Family income } \\
\hline
\end{tabular}

system. Employees' lack of awareness, insufficient facilities and problems related to the mother, can interfere with the implementation of quality care. At all stages, problems, obstacles and achievements will be shared with participants and will be rethought.

Action research can be considered as a suitable approach to apply knowledge in practice and to fill the gap between performance and research in a clinical situation. Applying this approach, after understanding and recognizing the problem in context facilitates more informed decisions to be made to change the situation [33].

Action research leads to the transformation of the current situation into a more desirable situation, and action is the main focus in this research type. The purpose of this action is to improve affairs and make them effective [34]. This method is the best approach in applying new processes in the system and creating sustainability. Change is considered as a part of the research process and is done in the form of a repetitive cycle, consisting of stages to recognize the problem or situation that needs change, planning, action and then finding the results of the action for planning and next action [33, 35].

Applying C-KMC requires the development of appropriate strategies, budget allocation and clear and coordinated planning at different levels of the health system [36]. It seems that the use of a participatory action 
research approach would be useful in introducing CKMC in the study hospital and the results could be used by health policy makers and planners to improve the quality of neonatal care.

\section{Abbreviations}

ANOVA test: Analysis of variance test; C-KMC: Continues kangaroo mother care; CPAP: Continuous positive airway pressure; NICU: Neonatal intensive care unit; WHO: World Health Organization

\section{Acknowledgements}

This study is a PhD dissertation. We would hereby like to thank the ViceChancellor for Research of Tabriz University of Medical Sciences for financial support.

\section{Authors' contributions}

$\mathrm{MM}, \mathrm{AMB}$ and $\mathrm{SH}$ : contribute to the study design. NS, LV contributed to qualitative section and action research section of protocol. MH, MBH contributed to the quantitative section of protocol. MM, SH and BSM, contributed to the implementation of protocol (both qualitative and quantitative section). MM, AMB, SH has written to the primary draft of protocol. $\mathrm{MH}$ and $\mathrm{MBH}$ contributed to writing final draft of protocol. All authors read the final draft critically and approved it.

\section{Funding}

This study is funded by Tabriz University of Medical Sciences.

\section{Availability of data and materials}

Not applicable.

\section{Ethics approval and consent to participate}

This protocol has been approved by the Ethics Committee of Tabriz University of Medical Sciences, Tabriz, Iran (reference number: IR.TBZMED.REC.1398.497). Written informed consent will be obtained from every participant.

\section{Competing interests}

The authors declare that they have no competing interests.

\section{Author details}

'Student Research Center Committee, Tabriz University of Medical Science, Tabriz, Iran. ${ }^{2}$ SAMRC Unit for Maternal and Infant Health Care Strategies and Research Centre for Maternal, Fetal, Newborn and Child Health, University of Pretoria, Pretoria, South Africa. ${ }^{3}$ Pediatric health research center, Tabriz University of Medical Science, Tabriz, Iran. ${ }^{4}$ Department of Midwifery, School of Nursing and Midwifery, Tabriz University of Medical Science, Tabriz, Iran. ${ }^{5}$ Department of Pediatric Nursing, Tabriz University of Medical Science, Tabriz, Iran. ${ }^{6}$ Taleghani Training Hospital, Tabriz University of Medical Science, Tabriz, Iran. ${ }^{7}$ Department of midwifery, School of Nursing and midwifery, Research center of psychiatry and behavioural science, Tabriz University of Medical Science, Tabriz, Iran.

\section{Received: 16 September 2020 Accepted: 8 February 2021} Published online: 08 March 2021

\section{References}

1. Baqui AH, Mitra DK, Begum N, Hurt L, Soremekun S, Edmond K, et al. Neonatal mortality within 24 hours of birth in six low- and lower-middleincome countries. Bull World Health Organ. 2016;94:752-8b.

2. Estimates developed by the UN Inter-agency group for child mortality estimation, Levels and trends in child mortality 2019. Available from: https:// www.unicef.org/reports/levels-and-trends-child-mortality-report-2019.

3. Valcamonico A, Accorsi P, Sanzeni C, Martelli P, La Boria P, Cavazza A, et al. Mid- and long-term outcome of extremely low birth weight (ELBW) infants: an analysis of prognostic factors. J Matern Fetal Neonatal Med. 2007;20:46571.

4. Enweronu-Laryea CC, Andoh HD, Frimpong-Barfi A, Asenso-Boadi FM. Parental costs for in-patient neonatal services for perinatal asphyxia and low birth weight in Ghana. PLoS One. 2018;13:e0204410.
5. Lawn JE, Cousens S, Zupan J, Team LNSS. 4 million neonatal deaths: when? Where? Why? Lancet. 2005;365:891-900.

6. World Health Organization. Survive and thrive: transforming care for every small and sick newborn. Geneva: World Health Organisation; 2019.

7. World Health Organization. WHO recommendations on interventions to improve preterm birth outcomes. Geneva: World Health Organisation; 2015.

8. Conde-Agudelo A, Diaz-Rossello JL. Kangaroo mother care to reduce morbidity and mortality in low birthweight infants. Cochrane Database Syst Rev. 2016:CD002771.

9. Akbari E, Binnoon-Erez N, Rodrigues M, Ricci A, Schneider J, Madigan S, et al. Kangaroo mother care and infant biopsychosocial outcomes in the first year: a meta-analysis. Early Hum Dev. 2018:122:22-31

10. Broughton El, Gomez I, Sanchez N, Vindell C. The cost-savings of implementing kangaroo mother care in Nicaragua. Pan Am J Public Health. 2013;34:176-82.

11. Kumar RK, Singhal A, Vaidya U, Banerjee S, Anwar F, Rao S. Optimizing nutrition in preterm low birth weight infants-consensus summary. Front Nutr. 2017:4:20.

12. Unar-Munguia M, Torres-Mejia G, Colchero MA, Gonzalez de Cosio T. Breastfeeding mode and risk of breast cancer: a dose-response metaanalysis. J Hum Lact. 2017;33:422-34.

13. Udani RH, Hinduja A, Rao S, Kabra N, Kabra S. Role of kangaroo mother care in preventing neonatal morbidity in the hospital and community: a review article. J Neonatol. 2014;28:29-36.

14. Mekonnen AG, Yehualashet SS, Bayleyegn AD. The effects of kangaroo mother care on the time to breastfeeding initiation among preterm and LBW infants: a meta-analysis of published studies. Int Breastfeed J. 2019;14:12.

15. Nyqvist KH, Anderson CG, Bergman N, Cattaneo A, Charpak N, Davanzo $\mathrm{R}$, et al. Towards universal kangaroo mother care: recommendations and report from the first European conference and seventh international workshop on kangaroo mother care. Acta Paediatr. 2010; 99:820-6.

16. Zaka N, Alexander EC, Manikam L, Norman ICF, Akhbari M, Moxon S, et al. Quality improvement initiatives for hospitalised small and sick newborns in low- and middle-income countries: a systematic review. Implement Sci. 2018;13:20.

17. UNICEF. The state of the world's children 2009: maternal and newborn health: UNICEF; 2008.

18. Charpak N, Tessier R, Ruiz JG, Hernandez JT, Uriza F, Villegas J, et al. Twentyyear follow-up of kangaroo mother care versus traditional care. Pediatrics. 2017;139(1):e20162063.

19. Namnabati M, Talakoub S, Mohammadizadeh M, Mousaviasl F. The implementation of kangaroo mother care and nurses' perspective of barriers in Iranian' NICUs. Iran J Nurs Midwifery Res. 2016;21:84-8.

20. Bergh AM, Arsalo I, Malan AF, Patrick M, Pattinson RC, Phillips N. Measuring implementation progress in kangaroo mother care. Acta Paediatr. 2005;94: $1102-8$.

21. McNiff J. Action research: principles and practice, London, Routledge. 3rd edition. Translation by Ahanchian M. 2013.

22. Polit DF, Beck CT. Nursing research: generating and assessing evidence for nursing practice: Wolters Kluwer Health/Lippincott Williams \& Wilkins; 2012

23. Mishra P, Rai N, Mishra NR, Das RR. Effect of kangaroo mother care on the breastfeeding, morbidity, and mortality of very low birth weight neonates: a prospective observational study. Indian J Child Health. 2017:4:379-82.

24. Hsieh HF, Shannon SE. Three approaches to qualitative content analysis. Qual Health Res. 2005;15:1277-88.

25. Speziale HS, Streubert HJ, Carpenter DR. Qualitative research in nursing: advancing the humanistic imperative: Lippincott Williams \& Wilkins; 2011.

26. World Health Organization. Standards for improving quality of maternal and newborn care in health facilities. 2016.

27. Najafi Anari H, Rassuli M, Atashzadeh Shoorideh F, Namdari M. Auditing preterm neonatal nutrition nursing care. Quart J Nurs Manag. 2014;2: 29-37.

28. Doerhoff R, Garrison B. Human factors in the NICU: a bedside nurse perspective. J Perinat Neonatal Nurs. 2015;29:162-9.

29. Hendricks-Munoz KD, Louie M, Li Y, Chhun N, Prendergast CC, Ankola $P$. Factors that influence neonatal nursing perceptions of family- 
centered care and developmental care practices. Am J Perinatol. 2010; 27:193-200.

30. Moore E, Bergman N, Anderson GC, Medley N. Early skin-to-skin contact for mothers and. Cochrane Database Syst Rev. 2016;11:CD003519.

31. Cong X, Ludington-Hoe SM, Walsh S. Randomized crossover trial of kangaroo care to reduce biobehavioral pain responses in preterm infants: a pilot study. Biol Res Nurs. 2011;13:204-16.

32. World Health Organization. Kangaroo mother care: a practical guide: World Health Organization; 2003.

33. Koshy V. Action research for improving educational practice: a step-by-step guide: SAGE; 2009

34. Rahman MA. Action and knowledgebreaking the monopoly with participatory action-research: Apex press; 1991

35. Loewenson R, Laurell AC, Hogstedt C, D'Ambruoso L, Shroff Z. Participatory action research in health systems: a methods reader: TARSC, AHPSR, WHO, IDRC Canada, Equinet; 2014.

36. Uwaezuoke SN. Kangaroo mother care in resource-limited settings: implementation, health benefits, and cost-effectiveness. Res Rep Neonatol. 2017:7:11-8

\section{Publisher's Note}

Springer Nature remains neutral with regard to jurisdictional claims in published maps and institutional affiliations.

Ready to submit your research? Choose BMC and benefit from:

- fast, convenient online submission

- thorough peer review by experienced researchers in your field

- rapid publication on acceptance

- support for research data, including large and complex data types

- gold Open Access which fosters wider collaboration and increased citations

- maximum visibility for your research: over $100 \mathrm{M}$ website views per year

At $\mathrm{BMC}$, research is always in progress.

Learn more biomedcentral.com/submissions 